\title{
Marco jurídico da comunidade muçulmana na Espanha: acordos de cooperação entre a Comissão Islâmica da Espanha e o Estado Espanhol
}

\author{
Esther Solano Gallego*
}

\section{Resumo}

O artigo analisa a situação jurídica e a organização representativa institucional da comunidade muçulmana de Espanha, focando, fundamentalmente, no estudo dos Acordos de Cooperação entre o Estado Espanhol e a Comissão Islâmica da Espanha em 1992. Estes Acordos, assinados, analogamente, com judeus e evangélicos, criam o marco legal de uma série de benefícios fiscais, laborais, educativos e sociais para as entidades islâmicas pertencentes à CIE, graças à denominação de religião de notório arraigo, concedida pela administração espanhola à religião islâmica. O estudo revisará os Acordos, os benefícios outorgados e os principais inconvenientes que impedem a viabilidade de alguns deles.

\section{Legal frame of Muslim community in Spain: Cooperation Agreements between Spanish Islamic Commission and Spanish State}

\begin{abstract}
This paper analyzes the legal context and representative institutional organization of Spanish Muslim Community, focusing, mainly, the study of Cooperation Agreements between Spanish State and Spanish Islamic Commission in 1992. These Agreements, also signed with Judaism and Evangelism minorities, create the legal frame for fiscal, labor, educational and social benefits, thanks to the notorious root denomination granted to the Islamic religion. The study will analyze these Agreements, benefits and main inconveniences for their practicability.
\end{abstract}

* Doctoranda del Instituto de Ciencias de las Religiones de la Universidad Complutense de Madrid. con el tema de investigación "Islam chií en Brasil". Email de contacto estsolano@ hotmail.com 


\section{Marco jurídico de la comunidad musulmana en España: Acuerdo de Cooperación entre la Comisión Islámica de Es- paña y el Estado Español}

\section{Resumen}

El siguiente artículo analiza la situación jurídica y la organización representativa institucional de la comunidad musulmana de España, examinando, esencialmente, los Acuerdos de Cooperación entre el Estado Español y la Comisión Islámica de España (CIE) de 1992. Estos Acuerdos, firmados análogamente con las confesiones judía y evangélica, suponen el marco legal para una serie de beneficios fiscales, laborales, educativos, sociales para las entidades islámicas pertenecientes a la CIE, en función de la denominación de religión de notorio arraigo, otorgada por la administración española a la religión islámica. El trabajo revisará los Acuerdos, proporcionando una visión de conjunto de los beneficios que se recopilan y los principales inconvenientes que impiden la viabilidad de algunos de ellos.

\section{Introducción}

La presencia del Islam en España es una de las realidades sociales que configuran la idiosincrasia religiosa del país. En pocos años y, tras la superación de una dictadura de corte nacional-católico, España cuenta con más de 1.000 .000 de musulmanes ${ }^{1}$. Se destacan, esencialmente los musulmanes de origen marroquí, debido a la proximidad geográfica e histórica que ha propiciado fuertes lazos de unión entre España y Marruecos. Tampoco podemos olvidar el creciente número de conversos españoles que pronuncian la Shahada (fórmula de fe del fiel musulmán necesaria para el proceso de conversión) diariamente en algunas de las numerosas mezquitas españolas.

Como ante cualquier otro análisis cuantitativo en el que intentamos describir numéricamente un fenómeno religioso, las posibles cifras a manejar por unas y otras entidades poseen graves márgenes de error y una enorme variabilidad. Si nos atenemos a los datos del Ministerio de Trabajo e Inmigración, las cifras que se nos presentan son las de aquellos inmigrantes originarios de países musulmanes con tarjeta de residencia o certificado de registro. Si estudiamos la distribución geográfica de los mismos, según los datos del mismo Ministerio, podemos comprobar que la gran mayoría de la población musulmana se asienta, fundamentalmente, en Cataluña (casi 300.000 musulmanes) seguida de Andalucía (120.000) y Madrid (80.000). Cantabria se sitúa como la comunidad autónoma con menos población inmigrante de países musulmanes (no llega a 1900). Sin embargo, las cantidades varían cuando consultamos el Estudio Demográfico de la Población Musulmana elaborado

\footnotetext{
1 Según datos del Informe Anual del Instituto Andalusí, en España vivían, en 2006 1.080.478
} musulmanes. 
en 2008 por UCIDE (Unión de de Comunidades Islámicas de España). Según este mismo informe, que recoge los datos del padrón municipal, un total de 220.478 ciudadanos residentes en la Comunidad de Madrid profesan la religión musulmana, siendo, 112.434 extranjeros y 107.984 españoles, siendo esta la distribución de extranjeros:

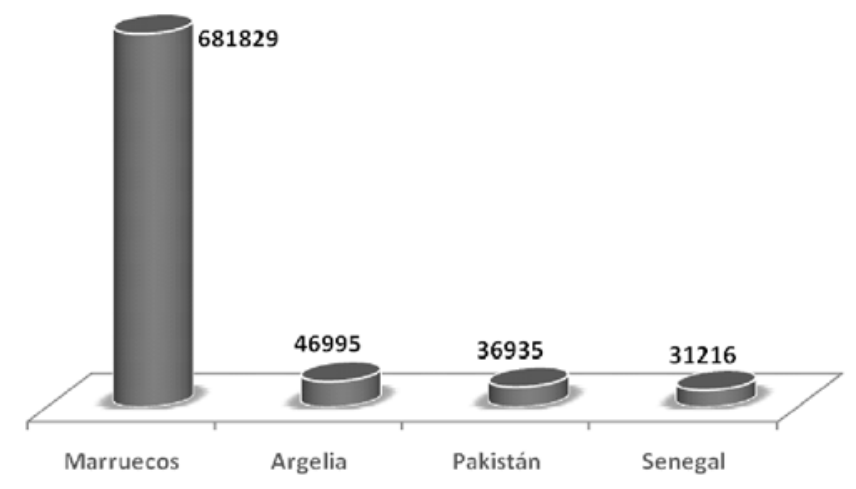

Inmigrantes en España por nacionalidades.

Fuente: Datos del Ministerio de Trabajo e Inmigración, 2008.

Elaboración propia

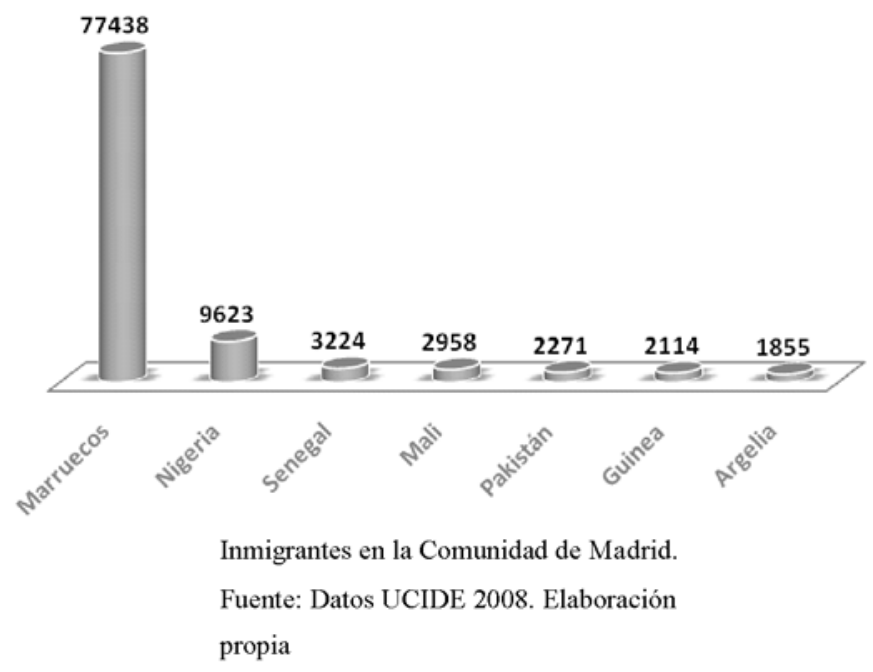


Es, sin duda, evidente, que la altísima proporción de musulmanes marroquíes en territorio español, configura la percepción social que se tiene del Islam, muy difícilmente desligado a las problemáticas relaciones de los sucesivos gobiernos españoles con el vecino Marruecos. Los términos "moro”, "marroquí" o "musulmán” son, habitualmente, empleados a manera de sinónimos, relegando a un plano muy inferior la diversidad extranjeros de múltiples orígenes que profesan la fe islámica, así como musulmanes de segunda generación en posesión de la nacionalidad española y un número cada vez más significativo de ciudadanos provenientes de familias españolas que, a menudo por motivos matrimoniales, se convierten al Islam.

\section{Organización Institucional del Islam en España}

La Ley de Libertad Religiosa de 1967, marca el inicio, en España, de una nueva etapa de libertad de creencias y respeto a la diferenciación religiosa. La nueva concepción legal de las minorías religiosas, asegura un contexto positivo para el asociacionismo musulmán español. A partir de iniciativas ceutí y melillense, ciudades con un activismo islámico superior al del la península por su peculiar localización, se crea en Madrid, en 1971, la Asociación Musulmana de España (AME) presidida por el sirio nacionalizado español Riay Tatary, responsable de la construcción de la primera mezquita moderna en territorio español. Tras el fin de la dictadura y el comienzo de la apertura religiosa, el converso Machordom Comins crea, en 1979, la Comunidad Musulmana de España, como organismo de competencia directa a la anterior institución. ${ }^{2}$ La división entre musulmanes de origen árabe y conversos, ya oficial en la con la creación de estas dos asociaciones, continúa, aún hoy, caracterizando las relaciones entre las comunidades islámicas españolas. Esta relación de bipolaridad histórica entre los órganos representativos del Islam, ha afectado y continúa afectando negativamente a las comunidades musulmanas, ralentizando e incluso paralizando, la puesta en práctica de numerosas políticas de integración y derechos de la población islámica, concedidos por la legislación.

En 1975, ya inaugurada la etapa democrática en España, se crea la comisión consultiva para el anteproyecto de la nueva Ley Orgánica de Libertad Religiosa (LOLR) actuando, como representante del Islam, la AME. La nueva ley, todo un hito histórico en el respeto a las minorías religiosas en territorio español, se publica en el Boletín Oficial del Estado en 24 de julio de 1980, derogando la anterior de 1967:

\footnotetext{
2 MORERAS, Jordi. Más allá de la memoria histórica. La viva presencia musulmana en España. In Musulmanes en Barcelona. Espacios y dinámicas comunitarias. Ed. CIBOD, Barcelona, 1999, p. 85-97.
} 
Las creencias religiosas no constituirán motivo de desigualdad o discriminación ante la Ley. No podrán alegarse motivos religiosos para impedir a nadie el ejercicio de cualquier trabajo o actividad o el desempeño de cargos o funciones públicas. (Art.2, LOLR, 1980)

La ley garantiza el derecho a todo creyente a profesar sus creencias, practicar su culto, guardar sus festividades, recibir asistencia y enseñanza religiosas y cultivar el asociacionismo religioso. Así mismo, prevé la creación de una Comisión Asesora de Libertad Religiosa, como órgano encargado de velar por su aplicación y la firma de Acuerdos de Cooperación con las religiones que hayan alcanzado la denominación de notorio arraigo.

Para la firma de dichos Acuerdos, el Estado instó a la creación de organismos vocales y representativos de las confesiones. En octubre de 1989 se funda la Federación Española de Entidades Islámicas (FEERI), comenzando las negociaciones con el ejecutivo en 1991. Meses después, un grupo de siete asociaciones se escinde de la FEERI, fundando la Unión de Comunidades Islámicas de España (UCIDE), dirigida desde sus inicios por Riay Tatary. Ambas organizaciones componen la Comisión Islámica de España (CEI), órgano encargado de la representación del Islam en España y el diálogo con el Estado. Una de las razones del estancamiento en el que se encuentran los tratados firmados hace años con el Estado, es esta composición bicéfala de la CEI. La Comisión Permanente está compuesta por seis miembros (tres por federación), ejerciendo su mandato por periodos de tres años. Dicha Comisión nombra a los Secretarios Generales, puede modificar los estatutos de la CIE, debe aprobar los presupuestos anuales, la admisión de solicitudes de nueva pertenencia de comunidades a la CIE y la revisión de cualquier asunto referente a los Acuerdos de Cooperación. Dado que las decisiones se toman por mayoría absoluta, podemos imaginar el enquistamiento constante que la caracteriza. Por otra parte, la cúspide formal de la CIE y su representación legal está formada por dos Secretarios Generales (de nuevo uno de la UCIDE y otro de la FEERI). La FEERI está conformada fundamentalmente por españoles conversos mientras que la UCIDE está dirigida a los musulmanes árabes y aglutina el mayor número de comunidades islámicas (prácticamente el 80\%). El converso Mansur Escudero lideró la FEERI hasta el año 2000. Tras su retirada, la FEERI quedó liderada por Abdel Karim Carrasco y ya en 2006 por Mohammad Ali. La falta de entendimiento de ambas organizaciones ha supuesto un grave problema para el avance de los derechos de la comunidad musulmana en España 
Se puede decir que ha perdido toda su capacidad real de acción y de cohesión entre las distintas comunidades islámicas del territorio español. Hay ya casi un clamor, cada vez menos escondido, de que la CIE no representa a la mayoría de los musulmanes y algunos incluso revelan desconocer su existencia (Aybar, 2009) ${ }^{3}$

\section{Los acuerdos de cooperación del Estado español y la cie sus repercusiones legales}

El marco jurídico deseado por cualquier minoría religiosa en España, es la firma de Acuerdos de Cooperación (AC) con el Estado Español, asegurando, así, un régimen de exención fiscal y derechos de preservación de sus actividades religiosas. El paso previo a la redacción de dichos Acuerdos, es conseguir la denominación de religión de notorio arraigo, un acto jurídico-administrativo del Estado español. Hasta el momento, las religiones calificadas como de notorio arraigo por el Estado Español son el Protestantismo, Judaísmo, Islam (1989) la Iglesia de Jesucristo de los Santos Últimos Días (2003), Testigos de Jehová (2006) y Budismo (2006) pero sólo se han firmado Acuerdos de Cooperación con musulmanes, protestantes y judíos (todos en 1992).

El Estado, teniendo en cuenta las creencias religiosas existentes en la sociedad española, establecerá, en su caso, acuerdos o convenios de cooperación con las Iglesias, Confesiones y Comunidades religiosas inscritas en el Registro que por su ámbito y número de creyentes hayan alcanzado notorio arraigo en España. En todo caso, estos acuerdos se aprobarán por Ley de las Cortes Generales. (Art. 7.1, LOLR, 1980)

El 25 de abril de 1989, la AME presenta una petición formal al Director General de Asuntos Religiosos ${ }^{4}$ para conseguir el status de notorio arraigo para la religión islámica. El 14 de julio de 1989, tras una reunión de la Comisión Asesora de Libertad Religiosa, el Islam queda definido jurídicamente como religión de notorio arraigo.

Que la religión islámica es de las creencias espirituales que han configurado la personalidad histórica de España. Nuestra cultura y tradición son inseparables de los fundamentos religiosos que han labrado las esencias más profundas del pueblo y del ser español. La religión islámica por su ámbito y su número de creyentes, ha alcanzado en la actualidad notorio arraigo en España. Dirección General de Asuntos Religiosos, 25/04/1989. Concesión del Notorio Arraigo

3 Entrevista de Mansur Escudero a Iván Jiménez Aybar, 07/02/2009. http://www.webislam. $\mathrm{com} /$ ?idt $=12210$

4 TATARY Riai. El Islam en España, desarrollo jurídico. Anales Congreso Islam y Musulmanes en España. Marco Jurídico y Social, 2007, Madrid. 
Los AC regulan los derechos de las minorías religiosas (derechos laborales, educativos, de construcción y mantenimiento de lugares de culto...) y, entre sus múltiples ventajas se encuentra la exención de impuestos a las comunidades que los firmen: Impuesto de Sociedades, Impuesto sobre Bienes Inmuebles y contribuciones especiales e Impuesto sobre Transmisiones Patrimoniales y Actos Jurídicos Documentados. Para que se hagan efectivos estos acuerdos, las entidades musulmanas que se acojan a ellos, deberán estar inscritas en el Registro de Entidades Religiosas, lo que les confiere personalidad jurídica propia y pertenecer a la CIE. Así mismo, los AC prevén la creación de una Comisión Mixta Paritaria, formada por representantes de la Administración estatal y la CIE que vele por su correcta puesta aplicación.

Veamos, a continuación, cuáles son los principales beneficios incluidos en los Acuerdos de Cooperación firmados con la Comisión Islámica de España:

\section{Lugares de culto y cementerios}

La inviolabilidad de los lugares de culto, se materializa, legalmente, en la aplicación de los artículos del Código Penal Español, 523, 524, 525. La profanación de los templos queda tipificada como delito que podrá ser consecuentemente castigo de entre 6 meses a un año.

El que en templo, lugar destinado al culto o en ceremonias religiosas ejecutare actos de profanación en ofensa de los sentimientos religiosos legalmente tutelados será castigado con la pena de prisión de seis meses a un año o multa de 12 a 24 meses. (Art. 524, Código Penal, 1995)

Los AC, reiteran este carácter legal de inviolabilidad, establecido de manera genérica por el Código Penal, materializándolo sobre los lugares de culto islámicos, entendiendo por tal, mezquitas, oratorios y cementerios.

Los lugares de culto de las Comunidades Islámicas miembros de la Comisión Islámica de España gozan de inviolabilidad en los términos establecidos por las Leyes (Art. 2.2. AC, 1992)

Los AC también recogen la protección a las tradiciones de islámicas de enterramientos:

Acuerdos de Cooperación: Se adoptarán las medidas oportunas para la observancia de las reglas tradicionales islámicas, relativas a inhumaciones, sepulturas y ritos funerarios que se realizarán con intervención de la Comunidad Islámica local (Art. 2.5. AC, 1992) 
Sin embargo, algunas prescripciones del derecho islámico funerario, entran en conflicto con el ordenamiento español, específicamente, el Reglamento de la Policía Sanitaria Mortuoria, por lo que, a pesar del bienintencionado artículo 2.5, no pueden llevarse a cabo, al contravenir la legalidad vigente española. Estas prescripciones, regidas por la jurisprudencia islámica, son el enterramiento sin ataúd y el enterramiento dentro de las 24 horas posteriores a la defunción, cuando legalmente, se establece en España el periodo entre 24 y 36 horas.

\section{Ministros de culto}

Una de las cuestiones más controvertidas sobre la regulación del Islam en España, en especial al partir del debate generado tras los atentados del 11-M, es el control estatal de los ministros de culto de los oratorios no registrados, las populares "mezquitas-garaje". Los AC, definen la figura del dirigente islámico, particularizando que han de poseer una certificación de la comunidad que lideran, así como la conformidad de la CIE.

A los efectos legales, son dirigentes religiosos islámicos e Imanes de las Comunidades Islámicas las personas físicas dedicadas, con carácter estable, a la dirección de las Comunidades a que se refiere el artículo 1 del presente Acuerdo, a la dirección de la oración, formación y asistencia religiosa islámica y acrediten el cumplimiento de estos requisitos mediante certificación expedida por la Comunidad a que pertenezcan, con la conformidad de la Comisión Islámica de España. (Art. 3.1, AC, 1992)

Los Acuerdos establecen una serie de regulaciones de la actividad de los ministros de culto, entre los que cabe destacar su función de ministrar el matrimonio contraído según la forma religiosa islámica, que tendrá efectos civiles siempre que se atenga a lo exigido por el Código Civil y previa inscripción en el Registro Civil y la asistencia religiosa en la Fuerzas Armadas. La presencia en las Fuerzas Armadas Españolas de personal de religión musulmana, así como de otras minorías religiosas, ha venido forzando al Estado, durante estos últimos años, a tomar las medidas precisas para asegurar el derecho a la asistencia religiosa plural, dentro de una organización, históricamente identificada con el catolicismo. Según los AC, los militares españoles, tendrán derecho a recibir asistencia religiosa islámica y se les facilitará la participación en ceremonias y fiestas islámicas:

Acuerdos de Cooperación: Se reconoce el derecho de los militares españoles musulmanes, sean o no profesionales, y de cuantas personas de dicha religión 
presten servicio en las Fuerzas Armadas, a recibir asistencia religiosa islámica y a participar en actividades y ritos religiosos propios del Islam, previa la oportuna autorización de sus Jefes, que procurarán hacer compatibles con las necesidades del servicio, facilitando los lugares y medios adecuados para su desarrollo.(Art. 8.1 AC, 1992)

El Estado se compromete a garantizar la asistencia religiosa en hospitales, centros penitenciarios, internados o centros asistenciales.

\section{Derechos laborales}

Uno de los derechos más exigidos por los musulmanes practicantes es la concesión de la posibilidad de interrumpir su jornada laboral los viernes para el rezo del Salat al-yumua, oración conjunta celebrada en la mezquita, así como la reducción de la misma durante el mes de Ramadán. Según los AC, el trabajador podrá solicitar interrupción laboral los viernes de las 13.30 a las 16.30 (franja horaria de la oración comunal del viernes válida para los horarios de verano e invierno). De la misma manera, podrá pedir al empleador la cesión de la jornada de trabajo una hora antes de la puesta del sol durante el Ramadán, para asegurar una conveniente ruptura del ayuno. Todos estos supuestos quedan supeditados al acuerdo previo entre empleador y empleado, por lo que, la gran mayoría de las ocasiones, son muy difícil consecución.

Los miembros de las Comunidades Islámicas pertenecientes a la Comisión Islámica de España que lo deseen, podrán solicitar la interrupción de su trabajo los viernes de cada semana, día de rezo colectivo obligatorio y solemne de los musulmanes, desde las trece treinta hasta las dieciséis treinta horas, así como la conclusión de la jornada laboral una hora antes de la puesta del sol, durante el mes de ayuno (Ramadán).En ambos casos, será necesario el previo acuerdo entre las partes. Las horas dejadas de trabajar deberán ser recuperadas sin compensación alguna.(Art. 12.1, AC, 1992)

Así mismo, los AC reconocen la opción de que las festividades islámicas más importantes puedan sustituir a las recogidas en el Estatuto de los Trabajadores

Las festividades y conmemoraciones que a continuación se expresan, que según la Ley Islámica tienen el carácter de religiosas, podrán sustituir, siempre que medie acuerdo entre las partes, a las establecidas con carácter general por el Estatuto de los Trabajadores, en su artículo 37.2, con el mismo carácter de retribuidas y no recuperables, a petición de los fieles de las Comunidades Islámicas pertenecientes a la Comisión Islámica de España. (Art 12.2, AC, 1992) 
Se citan las festividades de Al-Hiyra, el primer día del Año Nuevo Islámico, Achura, celebración del martirio de Hussein, prescriptiva para los musulmanes chíes, el día del nacimiento del profeta Mohammad, Al-Isra wa Al-Mi’ray o día en que se conmemora el Viaje Nocturno y la Ascensión del Profeta, la fiesta del Fitr que conmemora la culminación del Ramadán y la fiesta de Al-Adha, que celebra el sacrificio de Abraham.

\section{Educación}

La transición de la educación española de corte católico a una ecuación plural no religiosa, está suponiendo graves controversias en el seno de la sociedad española. Las diferentes iniciativas gubernamentales como suprimir la religión como materia cuya nota contabilizaba para el examen de selectividad o las nuevas asignaturas de Historia de las Religiones o Educación para la Ciudadanía, han levantado fuertes críticas en ciertos sectores sociales.

El Estado oferta la posibilidad del ofrecer clase de religión judía, evangélica e islámica en los colegios públicos, siempre que exista un número mínimo de 10 niños que los soliciten. Según los Acuerdos de Cooperación:

Se garantiza a los alumnos musulmanes, a sus padres y a los órganos escolares de gobierno que lo soliciten, el ejercicio del derecho de los primeros a recibir enseñanza religiosa islámica en los centros docentes públicos y privados concertados, siempre que, en cuanto a estos últimos, el ejercicio de aquel derecho no entre en contradicción con el carácter propio del centro. (Art. 10.1, AC, 1992)

El 23 de abril de 1996 se publica, por Resolución de la Subsecretaría del Ministerio de la Presidencia, el Convenio sobre Designación y Régimen Económico de las Personas Encargadas de la Enseñanza Religiosa Islámica en los Centros Docentes Públicos de Educación Primaria y Secundaria. Según dicho Convenio, al principio de cada etapa o nivel educativo o en el momento de al adscripción del alumno al centro, los padres o tutores del alumno deben informar al director del centro su deseo de recibir enseñanza religiosa islámica. Posteriormente, las administraciones educativas informarán a las comunidades islámicas de dichas solicitudes y la CIE designará a las personas que se considere adecuadas para la función de profesorado. Por tanto, la designación del profesorado sería competencia de la CIE pero el Estado se encargaría de la retribución económica del mismo. La hora de clase será compensada económicamente por el Estado siempre que el número a alumnos a los que se imparta sea igual o superior a 10. Los alumnos que reciban enseñanza religiosa islámica serán agrupados por un mismo nivel educativo. En caso que este grupo sea inferior a 10 personas se agruparán alumnos de diversos niveles educativos de una misma etapa 
En 1996, se publica el Currículo de Enseñanza Religiosa Islámica en los Centros Públicos y Concertados con el Estado donde se recogen los objetivos generales y los objetivos temáticos específicos, técnicas de evaluación y didáctica aplicadas en los cursos de primaria, secundaria y bachillerato en Enseñanza Religiosa Islámica. Según las directrices de este Currículo, en 2006 la editorial SM lanza el primer libro de religión islámica en Europa, Descubrir el Islam, para alumnos de primaria, en el que participan la UCIDE, la Fundación Pluralismo y Convivencia (creada por el Estado para velar por el cumplimiento de los derechos de las minorías religiosas y su integración) y la Dirección General de Asuntos Religiosos del Ministerio de Justicia.

El principal problema de la puesta en marcha de esta legislación es, de nuevo, la mala relación entre las dos federaciones que conforman la CEI, que no han logrado llegar a un acuerdo cerrado sobre la elección y contratación de profesores, por lo que la iniciativa se encuentra prácticamente paralizada.

El de jóvenes españoles que han solicitado estudiar la religión del Islam, se distribuyen por la geografía española de la siguiente manera: Andalucía (16.801) Aragón (3.028), Asturias (275), Baleares (3.213), Canarias (5.821), Cantabria (249), Castilla La Mancha (3.826), Castilla y León (2.095), Cataluña (31.165), Ceuta (5.301), Extremadura (3.164), Galicia (748), La Rioja (1.380), Madrid (18.713), Melilla (5.749), Murcia (7.588), Navarra (1.229), Comunidad Valenciana (8.013) y País Vasco (1.636). Sólo 41 profesores imparten educación religiosa islámica en la escuela pública, principalmente en Andalucía (16) Canarias (1), Ceuta (10) y Melilla (11).

\section{Alimentación Halal}

El Estado se compromete a garantizar la creación de un certificado Halal que distinga los productos alimentarios que se rigen por la jurisprudencia islámica. El Instituto Halal creado en 1999 por la Junta Islámica, comunidad integrada en la FEERI, es la entidad que gestiona la Marca de Garantía Halal. A dicha marca, registrada en 2003 en la Oficina Española de Patentes y Marcas, se han adscrito, hasta el momento, 71 empresas españolas. Por otra parte, desde 2008, dicha Junta ofrece la iniciativa Vida Halal, una asociación de consumidores destinada a la concienciación y la visibilización de la consumición Halal, así como el club de empresas Halal, para la distribución y comercialización de estos productos.

De acuerdo con la dimensión espiritual y las particularidades específicas de la Ley Islámica, la denominación Halal sirve para distinguir los productos alimentarios elaborados de acuerdo con la misma. (Art 14.1, AC, 1992) 
Según los AC, el Estado se compromete a procurar posibilitar comida Halal a los internados de centros públicos y establecimientos militares, alumnos musulmanes en centros docentes públicos y privados concertados, así como adecuar el horario de comidas durante el mes de Ramadán.

\section{- Conservación de patrimonio}

Los AC contemplan que la CIE y el Estado colaboren en la conservación y fomento del patrimonio islámico de España, mediante la creación de inventarios y la financiación de Fundaciones y Patronatos.

\section{Conclusiones}

La firma, en 1992, de los Acuerdos de Cooperación entre la Comisión Islámica de España y el Estado Español, posibilita un óptimo marco legal para la preservación de las prácticas religiosas de la comunidad musulmana en España. El derecho a una educación religiosa islámica pública, a jornadas de trabajo compatibles con las fiestas prescriptivas islámicas y el ayuno de Ramadán, así como a la asistencia religiosa islámica y comida Halal en el ejército, centros hospitalarios, cárceles, escuelas públicas o, los nada desdeñables, beneficios fiscales que favorecen a las entidades islámicas legalmente inscritas, suponen un incuestionable avance legislativo en lo referente al respeto y la integración social de las minorías religiosas. Sin embargo, la implantación de tan provechosa legislación, está resultando tarea compleja. La profunda división entre las instituciones musulmanas y, generalmente, entre el colectivo musulmán, así como la falta de madurez de la sociedad española para comprender y aceptar la práctica del Islam al mismo nivel de derechos que cualquier otra confesión religiosa, dificultan la puesta en marcha de la ley, perdiendo, así, una clara oportunidad brindada por el ejecutivo español de normalización de la religión islámica en territorio español.

\section{Bibliografía}

Musulmanes en España. Guía de Referencia Ed. Casa Árabe, Madrid, 2009

MORERAS, Jordi. Más allá de la memoria histórica. La viva presencia musulmana en España. In Musulmanes en Barcelona. Espacios y dinámicas comunitarias. Ed. CIBOD, Barcelona, 1999, p. $85-97$

TATARY Riai. El Islam en España, desarrollo jurídico. Anales Congreso Islam y Musulmanes en España. Marco Jurídico y Social, 2007, Madrid.

Acuerdo de Cooperación del Estado con la Comisión Islámica de España. http://noticias. juridicas.com/base_datos/Admin/126-1992.html

Convenio sobre Designación y Régimen Económico de las Personas Encargadas de la 


\section{Esther Solano Gallego}

Enseñanza Religiosa Islámica en los Centros Docentes Públicos de Educación Primaria y Secundaria

http://www.webislam.com/pdf/pdf.asp?idt=3695

Currículo de Enseñanza Religiosa Islámica

http:/ / www.webislam.com/?idt=176

Instituto Halal

http://www.institutohalal.com/ 